\title{
Roosttime restlessness in captive American Robins (Turdus migratorius)
}

\author{
LEONARD A. EISERER \\ Franklin and Marshall College, Lancaster, Pennsylvania 17604
}

\begin{abstract}
All-day observations of captive American Robins (Turdus migratorius) revealed that the birds became extremely active at dusk, the time when wild Robins typically fly some distance to a communal roost site. This roosttime restlessness occurred during every month of the year, and so was distinguishable from the migratory restlessness that the birds displayed during early morning hours of spring months. The present observations also uncovered a recapitulation effect, in that the changes in activity level that occurred within any single day (from dawn through dusk) tended to parallel the changes in activity level that occurred across the year (from spring through winter).
\end{abstract}

One fascinating, though scientifically neglected, aspect of the natural behavior of the American Robin (Turdus migratorius) is this bird's habit of flying to a communal roost site each evening and sleeping there with conspecifics. The strength of this habit appears to be quite powerful, for, though an individual Robin may occasionally spend the night in its own territory (e.g., see Graber \& Wunderle, 1966), apparently the only circumstance in which this regularly occurs is when the female has either eggs or nestlings to keep warm, and so always sleeps on her nest (Speirs, 1957). Otherwise, the communal roost is thought to be attended by adult males throughout the breeding season, by adult females when they first arrive at their breeding grounds (i.e., up until they begin laying eggs), by both sexes during the postbreeding/premigration period in late summer and early fall, by the season's offspring as soon as they can fly well enough to negotiate the trip to the roost, and by those Robins which spend the winter in the South (Black, 1932; Brewster, 1890; Howell, 1940; Speirs, 1957; Torrey, 1890; Widmann, 1895). Even migrating Robins may visit local roost sites as they pass through a given area en route to breeding grounds farther north in the spring (Howell, 1940) or to wintering grounds farther south in the fall (Speirs, 1957).

It should be realized that some of these conclusions about the Robin's roosting habits are primarily based upon the general observations of field researchers, and not upon data gathered on individually tagged or banded birds. Thus, some possibility remains that one or two of the above gener-

The author is indebted to Alan Kamil at University of Massachusetts, who provided the laboratory-reared birds used in this research. Reprint requests should be sent to Leonard A. Eiserer, Whitely Psychology Laboratories, Franklin and Marshall College, Lancaster, Pennsylvania 17604. alizations may not be entirely correct (e.g., malesparticularly before their first brood is flightworthymay, in fact, frequently sleep within their territories). Nevertheless, it does seem certain that communal roosting constitutes a major activity in the normal routine of wild Robins during a significant portion of their life cycle. If communal roosting characterizes Robins free in nature, it would perhaps not be surprising if some correlate of this habit were also observable in the behavior of Robins maintained in captivity.

As noted by Brewster (1890), wild Robins betray a characteristic restlessness around dusk as a preliminary to their flight to the roost. This restlessness struck Brewster as being quite similar to the preliminary restlessness that wild Robins show before migration commences (i.e., "migratory restlessness"). Since many birds show migratory restlessness when maintained in captivity during their normal migration season (Eyster, 1954; Palmgren, 1938; Pengelley \& Asmundson, 1971; Yokoyama \& Farner, 1978), captive Robins might be expected to similarly display "roosttime restlessness" during that time of day when they would normally be heading roostward.

The present work investigated this possibility via all-day observations of captive redbreasts. Although daily activity patterns have been described for numerous species of avians in captivity (Aschoff, 1967; Gwinner \& Eriksson, 1977; Ollason \& Slater, 1973; Palmgren, 1949), it appears that the American Robin-despite its great ubiquity in North Americahas yet to be studied in this context to any significant degree.

\section{EXPERIMENT 1}

\section{Method}

Subjects. Eight 21/2-year-old Eastern American Robins (Turdus migratorius migratorius) served as subjects. These birds had originally been removed from their nests in the Amherst, 
Massachusetts, area when they were approximately 10 days old. During their first 2 years of captivity, they were used in a variety of autoshaping experiments that bore no relation to the present work. Throughout this 2 -year period, the Robins had been maintained on a 12-h-light/12-h-dark illumination cycle.

The present study was conducted in Penn Yan, New York, several months after the Robins had been switched to a natural day-night cycle. More specifically, the birds were housed in individual cages in a room illuminated only by the sunlight entering from a single westward-facing window. The cages $(35 \times$ $50 \times 38 \mathrm{~cm}$ ) provided continuous access to both food and water and were equipped with two parallel perches that lay some $20 \mathrm{~cm}$ apart, one perch being approximately $8 \mathrm{~cm}$ higher than the other. Since the cages were separated by cardboard dividers, the Robins were visually isolated from one another; however, since all the cages were kept in a single room, the birds could nevertheless hear each other.

Procedure. Observations were taken on 2 separate days (October 12 and 14, 1976), both of which afforded essentially cloudless weather. On each of these days, the Robins were observed during 8-min periods that occurred every $20 \mathrm{~min}$ from 5:40 a.m. to $6: 20 \mathrm{p} . \mathrm{m}$. During these 8 -min periods, the behavior of each Robin was monitored for $60 \mathrm{sec}$ (i.e., Robin No. 1 was observed during the first minute, Robin No. 2 during the second minute, etc.). Throughout the observation periods, the investigator sat quietly in a chair about $2 \mathrm{~m}$ in front of the cages, in plain view of each of the birds. Although most contemporary research on activity patterns in captive avians entails mechanical recording rather than recording via a human observer, mechanical methods cannot readily monitor such behaviors as "inactivity"' (defined below) or preening.

The Robins' activities were quantified under two primary categories: (1) perch hops, the number of times per minute that a given bird moved from one of its perches to the other; and (2) inactivity, the number of seconds per minute that a given bird spent sitting quietly on its perch, not engaged in hopping back and forth, vocalizing, feeding or drinking, or flicking its tail or wings, etc.

Feeding, drinking, and preening were also monitored. The analysis of these behaviors is described under Experiment 2.

\section{Results}

Figure 1 shows the group mean seconds of inactivity (top graph) and mean number of perch hops (bottom graph) for each of the observation periods, averaged across both days of observation. As can be seen from the figure, the birds were completely inactive as of 6:00 a.m., a time which represented the end of the Robins' sleeping period (i.e., they had not yet stirred for the day, and in fact the room was still quite dark). Beginning at 6:20 a.m. and continuing through the early morning, the birds became relatively active, but this activity gradually decreased until the Robins entered a "loafing" period of extreme inactivity in the late morning and early afternoon. In turn, this loafing period-during which the birds spent $45-50 \mathrm{sec} / \mathrm{min}$ simply sitting quietly on their perches-ended rather abruptly at dusk when the Robins suddenly became very active. Indeed, the Robins then made considerably more perch hops than at any other time of day. This activity peak lasted a short while until the Robins settled down for the night.

Although vocalizations and tail/wing flicks were not specifically quantified, both of these behaviors
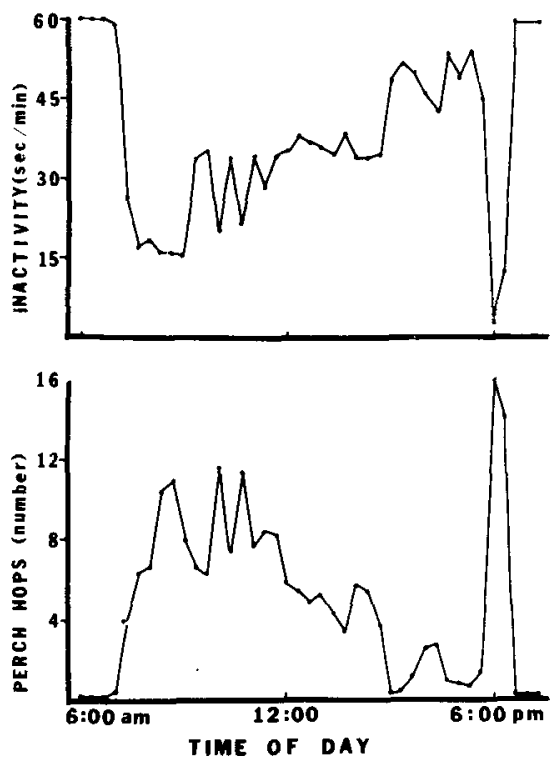

Figure 1. Group mean seconds of inactivity per minute (top graph) and group mean number of perch hops per minute (bottom graph), as a function of time of day.

appeared to parallel closely the function shown by the perch-hop data (i.e., fair amounts in early morning, low amounts during the afternoon, and finally high amounts at dusk). However, both behaviors also seemed to change qualitatively during the course of the day. At dusk, for example, vocalizations seemed to differ in frequency, intensity and rhythm compared to vocalizations at other times of day. And wing-flicking at dusk appeared to more closely represent flight-intention movements than at other times of day.

\section{Discussion}

Although the present work does not permit final conclusions concerning the degree to which a given Robin was influenced by sounds arising from its neighbors (vocalizations and the noises produced by hopping, wing-flicking, eating, etc.), the role of this interbird influence was probably quite minimal. At various times during the 2 days of observation, several Robins were quite active and noisy (e.g., in early morning or at the beginning of dusk) whereas their neighbors remained statuesque (i.e., because they had not yet stirred for the day, or had not yet entered the period of restlessness). This sort of time-lag among the Robins was sometimes as much as $\mathbf{3 0}$ min (i.e., some Robins stirred in the morning or became restless $1 / 2 \mathrm{~h}$ before other Robins did), and one would expect much better synchrony of behavior if the birds were being significantly influenced by one another. To be sure, some amount of apparent call-and-answer exchange did occur among the Robins, but such vocalizations were infrequent and typically of brief duration, and thus seemed not to affect the present data to any great extent. 
As can be seen from Figure 1, the inactivity data proved to be essentially the exact inverse of perch hops (i.e., whenever perch hops were maximal, in activity was minimal, and vice versa). While it is true that perch hops and inactivity should inherently be negatively correlated to at least some extent, the two measures need not have complemented each other as well as they did. Importantly, the low perch hopping that occurred during the loafing period cannot be interpreted as merely the result of an increase in some other activity (e.g., eating or drinking) since inactivity was maximal at that time; similarly, the low inactivity that was found at dusk cannot be interpreted as merely the result of increased feeding or drinking since perch hops were maximal at that time.

The loafing found in the present study may offer a somewhat distorted reflection of a comparable phenomenon existing in wild Robins. It is reasonable to suppose that relative to early morning levels of feeding, singing, etc., wild Robins do become more inactive in late morning or early afternoon. The degree of this inactivity, however, may be exaggerated under laboratory conditions where feeding takes unnaturally little time as well as effort. Nevertheless, the presently found loafing period is consistent with what appears to be a widespread, if not nearly universal, pattern of songbird activity under conditions of captivity-namely, a progressive decline in activity across the daylight period (Eyster, 1954; Ollason \& Slater, 1973; Palmgren, 1949; Smith, Brown, \& Mewaldt, 1969).

The presently found restlessness at dusk is similar to, though perhaps more marked than, the activity peaks that several other avian species show at the end of light periods (Aschoff \& Wever, 1965; Palmgren, 1949; Smith, Brown, \& Mewaldt, 1969). Of course, birds may show increased activity at dusk for reasons that have nothing to do with roosting-especially, for example, as part of normal feeding schedules. In the present work, however, the Robins did not engage in unusual amounts of feeding at dusk, but instead spent most of that time perch hopping, vocalizing, flicking their tails, and, most importantly, flicking their wings. Thus, the species' roosting habit would seem to be a plausible explanation for the restlessness found in the present research, particularly in light of Brewster's field observation that wild Robins become restless just before departing for the roost site.

One problem emanating from this interpretation is why the captive Robins did not show greater activity in the early morning than they did, since early morning is when wild Robins would be leaving the roost site. One might suppose, in other words, that the Robins should have been just as active in the early morning as they were at dusk. However, it may simply be that a state of restlessness is necessary to induce Robins to leave either their territories (during the breeding season) or their foraging areas (during the winter) but that such extreme physiological readiness is not needed to initiate their return.

Another problem with interpreting the activity peak at dusk as a correlate of the Robin's roosting habit is that the present data were collected during the fall, so that the peak activity may have, instead, merely reflected migratory restlessness. True, unlike the majority of other songbirds that migrate at night (Wallace \& Mahan, 1975, p. 340), Robins are primarily diurnal migrators and would therefore not be expected to show migratory restlessness just as the day was ending (Allen, 1961, p. 143; Baird \& Nisbet, 1960; Dorst, 1962). But it is possible that conditions of captivity either interfered with a normal diurnal preference or, alternatively, permitted a normal nocturnal preference to emerge through some disinhibitory process.

As a test of these possibilities, the Robins' daily activity pattern was assessed during each month of the year. If the activity peak at dusk is a correlate of migration, then it should only occur during spring and fall months. If the peak is, instead, a correlate of roosting, then it should occur during each month of the year, because Robins apparently travel to communal roosts during all four seasons.

\section{EXPERIMENT 2}

\section{Method}

Subjects. The eight Robins used in Experiment 1 also served as subjects in Experiment 2.

Procedure. The same observational procedures used in Experiment 1 (i.e., in October) were repeated during each of the succeeding 11 months; thus, on 2 days per month, each Robin was monitored for a 1-min period every 20 min from dawn to dusk. In choosing when to observe the birds during a given month, care was taken to select days that were not completely overcast with clouds, but were, instead, at least partly sunny (as it turned out, most observation days were predominantly sunny). Within that constraint, the 2 days fell as near to the middle of the month, and also as near to each other, as possible.

\section{Results}

Figure 2 shows for each month the group mean number of seconds of inactivity per minute as a function of time of day, averaged across the 2 days of observation. Figure 3 shows for each month the group mean number of perch hops per minute, also as a function of time of day and averaged across the 2 days of observation. Inspection of both sets of data reveals that the perch hop and inactivity measures were generally the inverse of one another, at least regarding the major trends emerging across the year.

As can be seen from both figures, the Robins showed essentially the same basic activity pattern 


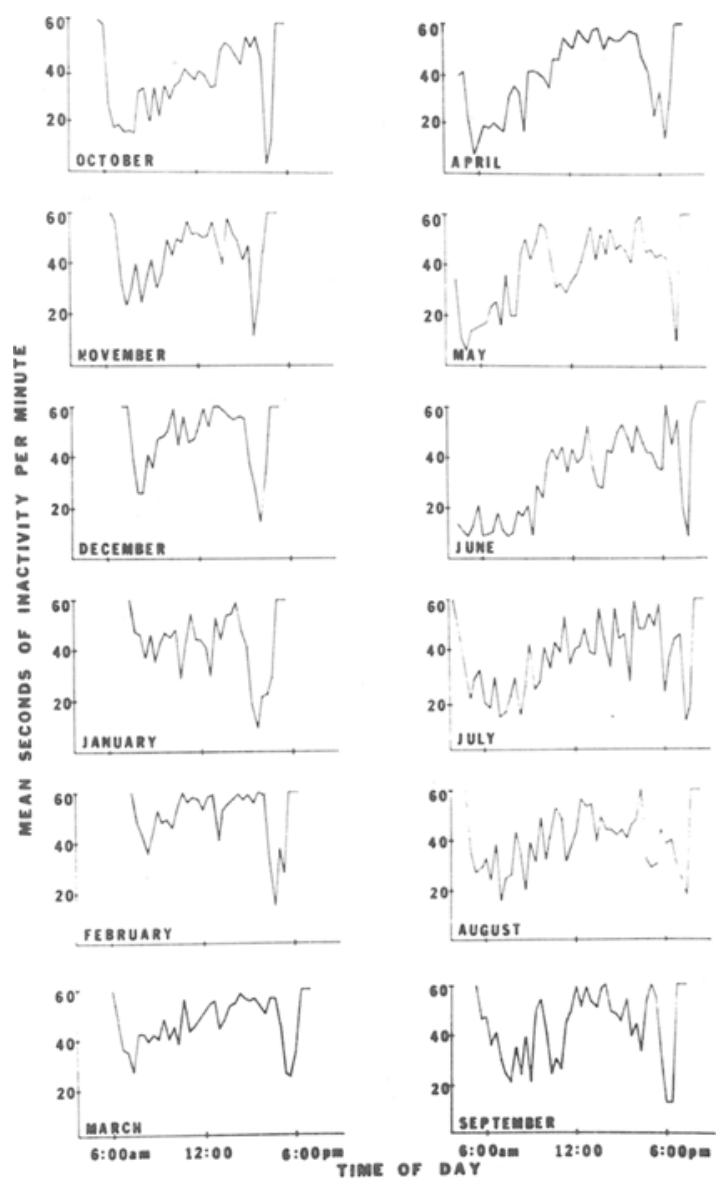

Figure 2. Group mean seconds of inactivity as a function of time of day, averaged across 2 days of observation, for each month of the year.

during all 12 months-namely, some amount of activity in the early morning evolved into a loafing period, which in turn was followed by a brief period of roosttime restlessness before the birds retired for the night. What changed most from month to month, however, was the degree of activity occurring during the early morning hours. More specifically, during the spring and early summer (April through June) the Robins were extremely active in the morning, more active than even at dusk; in contrast, a much more subdued level of activity occurred during the mornings of winter days (December through February).

The data on eating and drinking were analyzed by computing the proportion of 1-min observation periods during which the particular behavior occurred. Then, to assess possible seasonal changes, the data were grouped in terms of spring (March, April, May), summer (June, July, August), fall (September, October, November), and winter (December, January, February). Although there was a tendency for both eating and drinking to be most frequent in fall (the seasonal means for eating were $.08, .10$, .12 , and .08 , respectively; for drinking, .06, .08, .12 , and .08$)$, the seasonal changes were not significant ( $p>.18$ for eating and $p>.07$ for drinking).

The preening data, when analyzed in a comparable manner, indicated a significant seasonal effect, with preening being most frequent in the fall [spring, .01; summer, .05; fall, .09; winter, .03; $F(3,21)=8.01$, $\mathrm{p}<.001$ ]. A more detailed analysis on a month-bymonth basis then revealed that the fall increase occurred exclusively during the month of September, which was when the birds were in the height of molting (see Figure 4). A second analysis of variance was done on these month-by-month data, and confirmed the reliability of the September rise $[F(11,77)$ $=6.74, p<.001]$.

Eating, drinking, and preening were also analyzed in terms of possible frequency changes as a function of time of day. Naturally, length of the daylight period changed markedly from one month to another, but this problem was circumvented by dividing each day (from dawn to dusk) into successive fourths and then using these fourths as equivalent
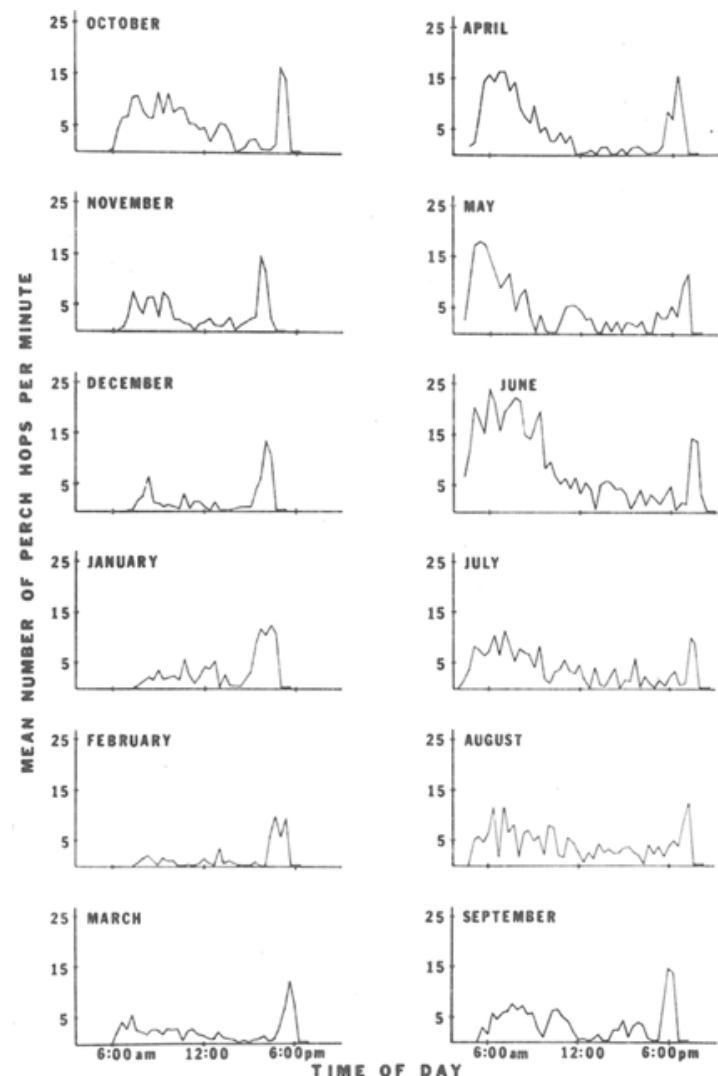

Figure 3. Group mean number of perch hops as a function of time of day, averaged across 2 days of observation, for each month of the year. 


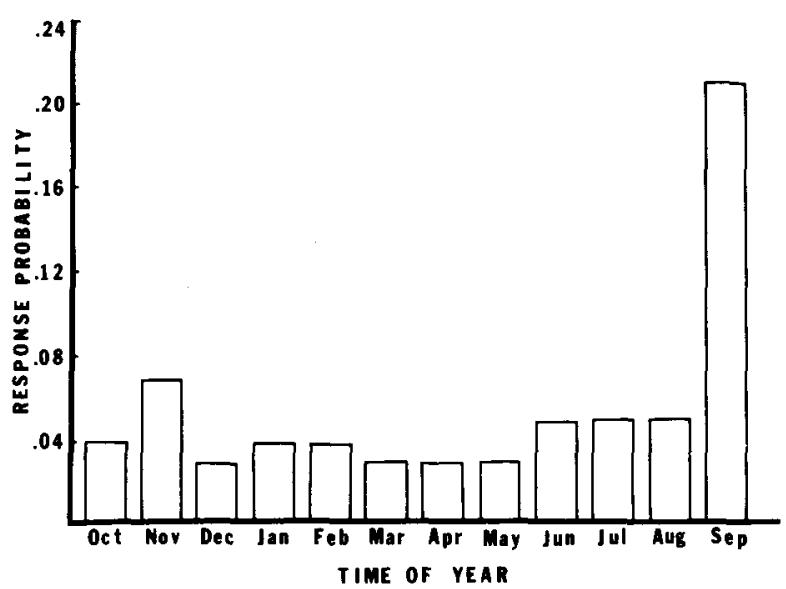

Figure 4. Probability of preening behavior, in terms of the proportion of 1-min observation periods during which at least some preening occurred, as a function of time of year.

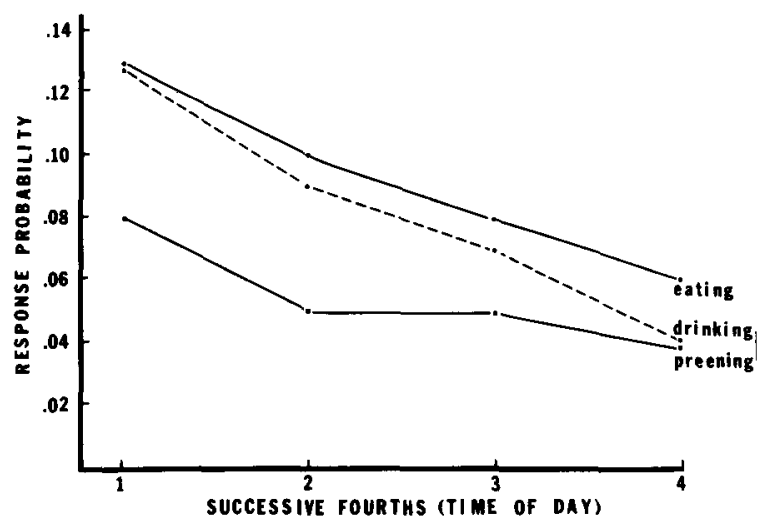

Figure 5. Probability of eating, drinking, and preening as a function of time of day, averaged across all months of the year.

units which could be averaged across months. Figure 5 shows the mean proportion of observation periods in which eating, drinking, and preening occurred as a function of successive fourths (i.e., as a function of time of day). As can be seen from the figure, all three behaviors declined as the day progressed. This general trend was reliable for eating $[F(3,21)=11.90, p<.001]$, for drinking $[F(3,21)$ $=9.90, \mathrm{p}<.001)$, and for preening, $[\mathrm{F}(3,21)=$ $6.78, \mathrm{p}<.01)$.

\section{Discussion}

The fact that restlessness at dusk appeared during every month of the year is strong evidence that it is not a correlate of the migratory urge but rather of the urge to fly to a communal roost site. Migratory restlessness would seem, instead, to be represented by the extreme aictivity that occurred during the early morning hours of April, May, and June (substantially less migratory restlessness may also be reflected in the fall by the noticeable rise in morning activity occurring in October relative to September and November). True, this April-June period extends well beyond the normal early spring migration season of wild Robins, but a similar finding of spring migratory restlessness persisting in captivity beyond the normal migration period has been reported for several other songbirds as well (Eyster, 1954; Merkel, 1958; Wagner, 1930). The occurrence of high morning activity in Robins during the spring is also consistent with field work indicating that Robins stand somewhat exceptional among songbirds by migrating during the day rather than at night; furthermore, other daytime migrators like the Green Finch and the Mountain Finch also display migratory restlessness in terms of increases in the peak of morning activity (Palmgren, 1943). Although the present findings suggest that wild Robins migrate primarily during the early hours of spring mornings (rather than, say, later in the afternoon), the present author knows of no field observations that either readily support or contradict this prediction.

Interestingly, three of the eight Robins in the present work also showed evidence of migratory restlessness at night during April, May, and June. More specifically, these birds usually remained quiet through the first several hours of the darkness period and then, as midnight approached, engaged in loud vocalizations and vigorous movements within their cages. These activities persisted more or less continuously for a couple of hours, whereupon the Robins grew quiet again until dawn. Interestingly, this pattern is similar to that of avian species considered to be true nocturnal migrators, as these birds typically enter a rest period after sunset before showing nocturnal unrest, which is in turn often followed by another rest period before dawn (Eyster, 1954; Smith, Brown, \& Mewaldt, 1969). While most authors generally agree that the American Robin is primarily a diurnal traveler, some have noted that Robins also occasionally migrate during darkness (Baird \& Nisbet, 1960; Chapman, 1912). The present observations, then, are consistent with the conclusion that Robins are primarily diurnal but occasionally nocturnal migrators. Weak nocturnal restlessness in a predominantly daytime migrator has also been reported for the Mountain Finch (Palmgren, 1943).

\section{GENERAL DISCUSSION}

It is interesting to consider that the phenomena of migration and roosting-as they occur in the American Robin-bear numerous similarities to each other. These similarities can be summarized as follows: (1) Both phenomena represent major rhythms in the Robin's life cycle, roosting being a daily rhythm and migration an annual one; (2) both involve significant distances to be traveled, up to 
several miles in the case of roosting and hundreds or even thousands of miles in the case of migration; (3) during both roosting and migration, Robins become flockers in sharp contrast to their daytime, breeding-season tendency towards territoriality (Brewster, 1890); (4) during both roosting and migration, Robins appear to become unusually timid and wary at the approach of humans (Eiserer, 1976, pp. 151-152); (5) just before embarking for the roost site or beginning their fall migration, wild Robins display a discernible "preparatory restlessness" (Brewster, 1890); and (6) as indicated by the present work, both roosting and migratory tendencies appear to be reflected in behavioral restlessness when Robins are kept in captivity. It could also be noted here that an adaptive link may connect roosting and migration, inasmuch as the daily flights to the roost during the breeding season may help prepare the year's offspring for the upcoming fall migration (Chapman, 1916, p. 19; Merriam, 1898, p. 19). (Another possible function of the Robin's roosting habit is that of providing a continuing local "census," which in turn could be instrumental in self-regulation of the Robin population; Barash, 1977, p. 71.)

There are also, to be sure, significant differences between roosting and migration. Migration, for example, is accompanied by marked changes in fat deposition, gonadal size, and endocrine activity; the first two of these changes obviously cannot accompany the daily roosting tendency, and any endocrine changes that may occur are likely to be less pervasive at the very least. Migratory restlessness, moreover, is probably accompanied by a preferred compass orientation (south in the fall, north in the spring), whereas roosttime restlessness probably is not. Despite these differences, however, the many points of marked parallel between roosting and migration are impressive.

This sort of analysis-i.e., comparing part of the Robin's daily activity pattern to part of its annual activity pattern-can be carried still further. If one were to assess the activity level of wild Robins on a season-by-season basis, one would find that the birds are quite active in spring and early summer, for they then are migrating north, establishing territories, winning mates, and engaging in all the continuous activities that the raising of offspring entails. Towards late summer and early fall, however, Robins enter a postbreeding state of relative inactivity; they gather in feeding and loafing flocks, and they also progress through the lethargic process of molting. Next, rather abruptly, fall migration commences and the birds are thrown into a flurry of activity as they head southward. Finally, during the winter, their activity level probably remains fairly low relative to levels sustained during the breeding and migration seasons. However, Robins are by no means entirely sedentary during the winter (Speirs, 1956).

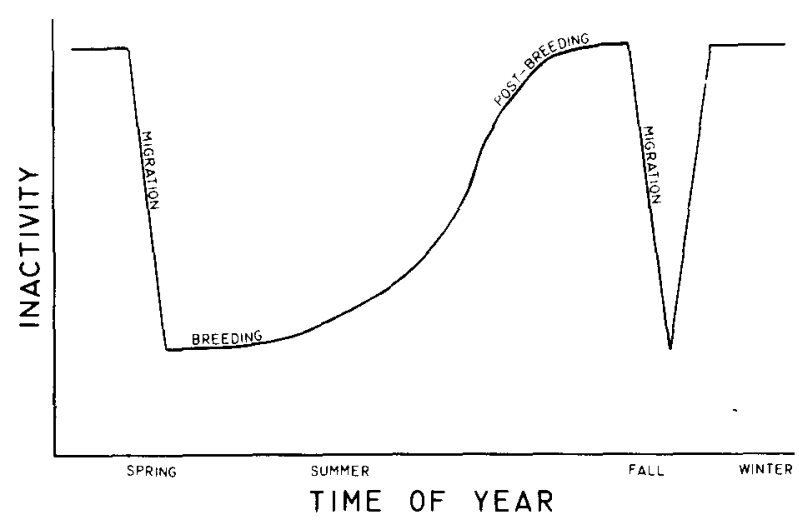

Figure 6. Hypothesized annual activity pattern for free-living American Robins.

Based upon these considerations, a hypothetical depiction of the Robin's yearly activity pattern (plotted in terms of inactivity) is presented in Figure 6. Obviously, the function portrayed in Figure 6 is markedly similar to the function presented in the top graph of Figure 1. Thus, in at least a general way, the Robin's daily activity pattern would seem to recapitulate its hypothesized yearly activity pattern.

Obviously, any empirical attempt to determine the validity of the hypothesized annual activity pattern presented in Figure 6 would be extremely difficult in wild, free-living Robins. It is possible, however, that aspects of the present data on captive Robins can be brought to bear on this issue. Since the morning activity peak is the part of the Robin's daily rhythm that changes most from one month to another, measures of the peak may be used as relatively sensitive indices of annual trends in overall activity level. Figure 7 shows, for each month of the year, the group mean seconds of inactivity averaged over the first $2 \mathrm{~h}$ of each of the 2 days of observation. The resulting function clearly resembles the

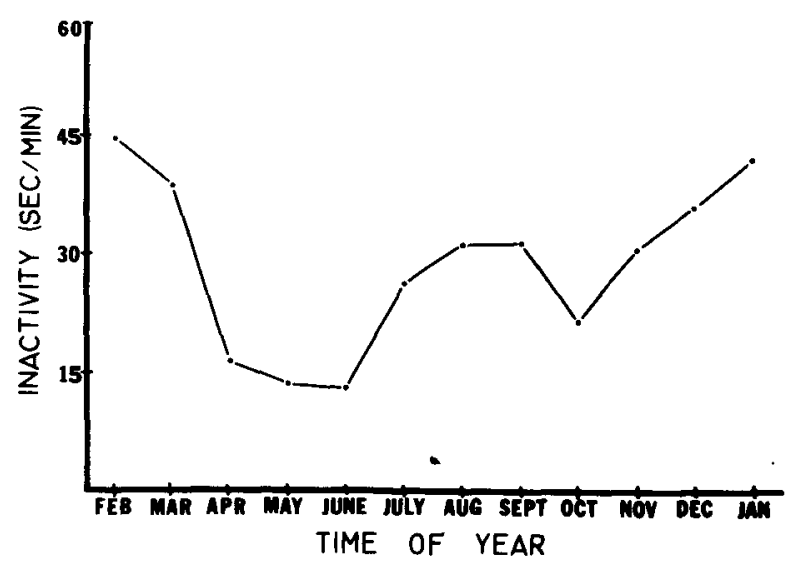

Figure 7. Group mean seconds of inactivity averaged over the first $2 \mathrm{~h}$ of both observation days during each month of the year. 
hypothesized pattern presented in Figure 6, as well as the actual daily function presented in Figure 1.

The daily activity pattern of captive Robins, then, does in fact recapitulate the annual activity pattern of such birds. Why this should be so is unclear. On the one hand, the recapitulation phenomenon may be mere (albeit remarkable) coincidence; on the other hand, it is possible that a causal connection exists here. For example, the same brain structures may mediate both of these activity patterns, and these structures may inherently operate in basically the same fashion whether functioning on a shortterm (daily) or a long-term (annual) cycle. Strong support for this suggestion of common physiological substrates are the many aforementioned similarities between roosting (a particular part of the daily cycle) and migration (a particular part of the annual cycle).

Figure 7 is also important in showing that the annual activity pattern of captive Robins closely resembles the annual activity pattern previously hypothesized for Robins free in nature. This finding, in turn, lends credence to the suggestion that the daily activity pattern shown by captive Robins is a reasonable parallel of the daily activity pattern of Robins free in nature. Put in more general terms, the validity of observing captive Robins in order to better understand the behavior of wild Robins finds support in the present work.

\section{REFERENCES}

AlLEN, A. A. The book of bird life. Princeton, N.J: Van Nostrand, 1961.

Aschoff, J. Circadian rhythms in birds. Proceedings of the XIV International Ornithology Congress, 1967, 81-105.

Aschoff, J., \& WEVER, R. Circadian rhythms of finches in lightdark cycles with interposed twilights. Comparative Biochemistry and Physiology, 1965, 16; 507-514.

BAIRD, J., \& Nisbet, I. C. T. Northward migration on the Atlantic coast and its relation to offshore drift. $A u k, 1960$, 77, 121-130.

BARASH, D. P. Sociobiology and behavior. New York: Elsevier North-Holland, 1977.

BLACK, J. D. A winter robin roost in Arkansas. Wilson Bulletin, 1932, 44, 13-19.

Brewste , W. Summer robin roosts. $A u k, 1890,7,360-373$.
Chapman, F. M. Bird-life. New York, N.Y: Appleton, 1912

Chapman, F. M. The travels of birds. New York: Appleton, 1916.

Dorst, J. The migrations of birds. Boston: Houghton Mifflin, 1962.

EISERER, L. A. The American robin: A backyard institution. Chicago: Nelson Hall, 1976.

Eyste R, M. B. Quantitative measurement of the influence of photoperiod, temperature, and season on the activity of captive songbirds. Ecological Monographs, 1954, 24, 1-28.

Graber, R. R., \& Wunderle, S. L. Telemetric observations of a robin. $A u k, 1966,83,674-677$.

Gwinner, E., \& Eriksson, L. Circadian rhythms and photoperiodic time measurement in the starling (Sturnus vulgaris). Journal of Ornithology, 1977, 118, 60-67.

Howell, J. C. Spring roosts of the robin. Wilson Bulletin, 1940, 52, 19-23.

MerKeL, F. W. Untersuchungen über tages- und jahresperiodische Änderungen im Energiehaushalt gekäfigter Zugvögel. Zeitschrift für vergleichende Physiologie, 1958, 41, 154-178.

Merriam, F. A. Birds of village and field. Boston: Houghton Mifflin, 1898.

Ollason, J. C., \& Slater, P. J. B. Changes in the behaviour of the male zebra finch during a 12-hr. day. Animal Behaviour, 1973, 21, 191-196.

Palmgren, P. Studien über den zeitlichen Ablauf der Zegurregung bei gekäfigten Keinvögeln I. Ornis Fennica, 1938, 15, 1-16.

Palmgren, P. Zur Tagesrhythmik der Fingenvögel. Ornis Fennica, 1943, 20, 99-103.

Palmgren, $P$. On the diurnal rhythm of activity and rest in birds. Ibis, 1949, 91, 561-576.

Pengelley, E. T., \& Asmundson, S. S. J. Annual biological clocks. Scientific American, 1971, 224, 72-79.

Smith, R. W., Brown, I. L., \& Mewaldt, L. R. Annual activity patterns of caged non-migratory white-crowned sparrows. Wilson Bulletin, 1969, 81, 419-440.

Speirs, J. M. The migratory phase of robin behaviour. Federation of Ontario Naturalists Bulletin, 1956, 72, 20-27.

Speirs, J. M. Robins roosts. Federation of Ontario Naturalists Bulletin, 1957, 76, 18-23.

Torkey, B. Robin roosts. Atlantic Monthly, 1890, 66, 492-498.

WAGne R, H. O. Über Jahres- und Tages rhythmus bei Zugvögeln. Zeitschrift für vergleichende Physiologie, 1930, 12, 703-724.

Wallace, G. J., \& Mahan, H. D. An introduction to ornithology (3rd ed.). New York: MacMillan, 1975.

Widmann, O. A winter robin roost in Missouri. $A u k, 1895$, 12, 1-11.

Yokoyama, K., \& Farner, D. S. Induction of Zugunruhe by photostimulation of encephalic receptors in white-crowned sparrows. Science, 1978, 201, 76-79.

(Received for publication September 21, 1978; revision accepted November 30,1978 .) 